\title{
4 On the challenges and drivers of implementing responsible innovation in foodpreneurial SMEs
}

\author{
Cristina Covello and Konstantinos Iatridis
}

\subsection{Introduction}

Responsible research and innovation or responsible innovation (RI) has recently attracted a lot of scholarly interest, leading to fruitful streams of research ranging from discussions about the responsibility of researchers in research and development (R\&D) teams (Pandza \& Ellwood, 2013) to theoretical frameworks of RI (Genus \& Stirling, 2018; Stilgoe et al., 2013; Voegtlin \& Scherer, 2017) and risk management approaches to lessen the negative externalities of innovations developed in publicly funded academic research (Owen et al., 2013). At the same time, driven by the fact that the vast majority of research and innovation takes place in the private sector, a burgeoning stream of research focuses on the implementation of RI in industry (Auer \& Jarmai, 2018; Dreyer et al., 2017; Hemphill, 2016; Iatridis \& Schroeder, 2016; Martinuzzi et al., 2018; Stahl et al., 2017; van de Poel et al., 2017). The insights generated from these studies have diffused the concept at industry level but there is a dearth of research focusing on RI and small and medium-sized enterprises (SMEs). This is an important gap in the literature as the vast majority of firms fall into this category. In the words of the European Commission, SMEs are the "backbone of the European economy", making up 99\% of the businesses in the EU (European_ Commission, 2018). Therefore, learning more about the challenges and drivers SMEs might face when implementing RI presents an opportunity for RI to ensure that SME strategy is aligned with the European Commission's vision for growth.

In this chapter, we aim to enhance knowledge of this topic by focusing on a specific category of SMEs active in the food industry. These firms, also known as "foodpreneurial", are SMEs with innovative food ideas, from artisan products to cutting-edge food technology. Foodpreneurial SMEs represent an interesting case for research because businesses of this type tend to have a startup mentality and use socially responsible business models to tackle issues as disparate as social inclusion and fighting disease. At the same time, foodpreneurial SMEs are disrupting big food and beverage producers at an alarming rate. In the USA, the top 25 food and beverage producers lost $\$ 18 \mathrm{~B}$ in market share 
between 2009 and 2015 (Kowitt, 2015). Equally in the UK, such SMEs seem to play a gradually increasing role. For instance, Pip and Nut, a UK nut butter brand that claims to be a healthy alternative to sugar and palm oil-filled conventional nut butters, is a prime example of this type of challenger brand. In just four years, the company has captured approximately $13 \%$ of the UK nut butter market (Newsdesk, 2018). Perhaps foodpreneurial SMEs have found a way to see the "grand challenges" of our time as an opportunity rather than a constraint. They are establishing innovative business models that put responsibility higher on the agenda than large firms. For this reason, there may be a natural tendency for such SMEs to innovate responsibly.

This chapter contributes to the literature both empirically and theoretically. Empirically, we introduce new interview data with 19 foodpreneurial SMEs operating in London, UK. Theoretically, we contribute to the literature by providing insights on the challenges and drivers SMEs face when implementing RI. Our results suggest that lack of awareness, time, labour and money imposes obstacles to RI. Inclusion proves to be equally tricky, as most respondents had difficulties identifying stakeholders and articulating how they engaged with them. Respectively, and opposite to the enlightened self-interest perspective found in many orthodox economic arguments, our findings highlight personal values and a concern for societal and environmental wellbeing as business drivers. This illustrates that, despite contemporary pressures for quarterly-based profit maximisation, there are SMEs that resist such demands and attribute the same, if not higher, significance to societal and environmental issues as they do to profit.

The chapter is organised as follows. First, we discuss the literature of RI in industry to act as a frame of reference with which to compare RI to already embedded RI practices in the SMEs studied. We then discuss the research methodology and findings of our analysis, with a focus on the challenges and drivers of implementing RI in the aforementioned SMEs. We conclude by discussing the implications of the study, its limitations and directions for future research.

\subsection{Literature review}

RI prioritises the integration of responsibility in R\&D processes. The literature suggests that innovation outcomes can be considered responsible when they are environmentally sustainable, ethically acceptable and socially desirable (von Schomberg, 2013). Environmental sustainability prioritises a responsible use of natural resources during the innovation processes while ethical acceptability proposes that innovation outcomes need to be in line with widely accepted norms and values in society. In turn, societal desirability suggests that innovation outcomes should contribute to the solution of key challenges facing humanity.

To achieve these ends, the literature suggests that innovators should anticipate the outcomes of innovation and possible consequences (both 
intended and unintended) for broader groups. Additionally, RI highlights the need for auditing and reviewing mechanisms during innovation processes to constantly reflect on each stage of an innovation, ensuring potential problems are identified and managed appropriately and timely, or prevented altogether. The inclusion of stakeholder groups at the early stages of innovation is perceived as one of the most important aspects of RI, as early engagement is believed to improve the chances for the innovation outcome to be in line with stakeholders' social, environmental and ethical demands. It is important to notice that in the private sector inclusion is based on the assumption that the most effective approach for companies is to prioritise the various stakeholder demands based on stakeholder salience (Mitchel et al., 1997). Furthermore, RI demands that researchers and innovators respond openly and transparently to all those, directly or indirectly, affected by the outcome of innovation (Stilgoe et al., 2013).

Recently, scholars have started addressing how some of the abovementioned points can be undertaken by industry. For instance, Lubberink et al. (2017) in their literature review of RI in industry found that existing studies focusing on inclusion prioritise clients and end-users, at the expense of including wider social groups in innovation processes. In turn, Van de Poel et al. (2017) discuss ways of developing key performance indicators, which can facilitate auditing and monitoring RI implementation. Their insights provide a useful first step for assessing and benchmarking RI implementation in industry. Equally, Gurzawska et al. (2017) argue that RI integration into corporate processes can be achieved by broadening the inclusion approach and taking into account the views of not only consumers but also employees and institutional actors. Respectively, Garst et al.'s (2017) study focuses on firms operating in the food industry, and analyses corporate motives for adopting RI practices. The authors conclude that both internal motives, such as profit maximisation and moral duty, as well as external drivers, such as regulation and legitimacy, play an important role in firms' decision to engage with RI. Similarly, Chatfield et al. (2017) focus on corporate motives but also take into account obstacles in the implementation of RI. Although they argue that economic motives play an important role in the adoption of RI, these authors found that there are cases of companies that have been able to balance financial and altruistic goals.

At the same time, a handful of studies have focused on the implementation of RI in SMEs. Pavie et al.'s (2014) study argues that SMEs' peculiarities, such as the fact that they are more flexible and less restricted by formal policies and procedures, make them ideal entities for experimenting with emerging technologies that tackle societal challenges. The authors envision SMEs as critical to RI dissemination and suggest that, by working in niche markets, SMEs can experiment until the proposition becomes attractive enough for large incumbents to acquire the SME and bring the innovation to a larger market. Policy instruments that broker relationships between academia, incumbents and start-ups could facilitate experimentation by helping 
a range of stakeholders interact - from suppliers, to users, to competitors. The authors state that a pre-requisite for SMEs engaging in experimentation is recognising the added value generated by such an approach. However, the authors discuss neither the resource constraints SMEs face nor how SMEs should find the resources to experiment and interact with stakeholders.

Some authors claim that resource constraints endured by SMEs might not necessarily be a bad thing but can rather be seen as a source of innovative thought. For instance, Gibbert et al. (2007) argue that resource constraints actually lead to better innovation as "would-be innovators facing constraints are more likely to find creative analogies and combinations that would otherwise be hidden under a glut of resources" (p. 16). Halme and Korpela's (2014) study of 13 SMEs developing RIs in Scandinavia reached similar findings. They looked at the quality, quantity and combinations of resources in SMEs that have successfully commercialised their innovations to uncover the resource conditions necessary for RI. What they found was that all SMEs needed at least some financial capital to innovate but that SMEs with financial resource constraints could compensate with social networks.

\subsection{Method}

We adopted a qualitative research framework, whereby we collected and analysed interview data to enrich theory. The sample of informants was purposively selected by the researchers, who identified the respondents as being theoretically relevant to the study's purpose (Silverman, 2006). We chose 19 foodpreneurial SMEs, of which 12 did not have a specific social purpose, four had a clear social purpose mission but they could not be classified as social enterprises and three could be classified as social enterprises (see Table 4.1 for participant and interview details). Seven of the participant SMEs belonged in the primary researcher's professional network, and they were chosen because the researcher was familiar with their innovative and ethical business practices. These seven were studied first, and the findings that emerged informed the selection of subsequent participants. The other 12 participants were found through online research. Their suitability for the project was determined from their websites and they were approached through cold calling. All interviewees held the title of either owner/manager or co-founder, which means that each had in-depth knowledge of the business' purpose, strategy and approach to responsibility. The interviews were conducted in both private and public spaces, all of which offered a quiet and private setting. Each interview was recorded, and the parts of interviews that were deemed interesting and useful were transcribed (Bogdan \& Biklin, 1998; Creswell, 2009; Seale \& Silverman, 1997; Silverman, 2006). Respondents were guaranteed compliance with ethical restrictions, such as those relating to informed consent, anonymity via the use of pseudonyms and avoidance of harm and deception (Fontana \& Frey, 2005), and were informed that they could opt out of the research at any time. 
Table 4.1 Profile of respondents

\begin{tabular}{llcl}
\hline Participant & Business type & $\begin{array}{l}\text { Number of } \\
\text { employees }\end{array}$ & $\begin{array}{l}\text { Interview } \\
\text { length } \\
\text { (minutes) }\end{array}$ \\
\hline 1 & Tea blender and wholesaler & 3 & 75 \\
2 & Online retailer of craft food & 13 & 60 \\
3 & Chocolatier & 10 & 45 \\
4 & Cold brewed coffee & 7 & 71 \\
5 & Sugar- and sweetener-free fizzy drinks & 10 & 45 \\
6 & Tea blender and wholesaler & 2 & 38 \\
7 & Hydroponic vegetable-growing appliance & 7 & 38 \\
8 & Bean to bar chocolate maker & 10 & 65 \\
9 & Beer brand & 7 & 40 \\
10 & Bakery & 3 & 46 \\
11 & British pulses wholesaler & 4 & 50 \\
12 & Honey production and hive rental & 2 & 50 \\
13 & Cheesemonger & 3 & 50 \\
14 & Hydroponic vegetable grower & 7 & 39 \\
15 & Community-supported fishing and online & 2 & 56 \\
& retailer & & \\
16 & Food-ordering app & 1 & 46 \\
17 & Sauce producer and street food & 2 & 35 \\
18 & Honey producer and bee farmer & 2 & 80 \\
19 & Craft brewer & 3 & 55 \\
\hline
\end{tabular}

The interview questions (Table 4.2) were framed according to the purpose of the research and focused on the SMEs' motivations to adopt RI and the obstacles they faced during implementation. Interview lengths ranged from 35 minutes to 1 hour and 15 minutes, with most hovering near the 47minute mark. The interviews were all run by a key member of the research team, who is working in the food industry and could "talk shop" with the respondents. Interviews took place in person and via telephone, on a one-toone basis. The researcher would recapitulate the interviewees' answers to let the respondent assess the adequacy of the interviewer's interpretation (Healey \& Rawlinson, 1994). In line with the relevant literature discussing bias control in interviews and ensuring data reliability (Healey \& Rawlinson, 1994; Saunders et al., 2012), following each interview the researcher recorded the information about the location, date and time, setting, and the researcher's immediate impression of how the interview went. To gain further insights into the accuracy of the respondents' answers, the interviewer took reflective notes that included observations of the participants and key ideas pertaining to the research themes. Additionally, the research relied on data from the company's website and relevant secondary data from journals, governmental sources and project deliverables to inform the interview questions and help build rapport between the interviewer and interviewee. 
Table 4.2 Interview questions

1. Can you tell me about what you do, about your business and how you got started?

2. What does the term Responsible Research and Innovation mean to you?

3. Can you tell me about your company's innovation strategy? Do you have one? How does it work?

4. Why do you think your business strategy is innovative?

5. Can you provide examples of how your company acts responsibly?

6. Can you think of an ethical dilemma or tricky situation your business has had to resolve? How did you resolve it?

7. What incentives are there for running your business responsibly?

8. Can you talk about how societal challenges affect your business?

9. How do you engage with internal and external stakeholders on these issues?

10. Are you responsive to what you learn from stakeholders?

11. How do you integrate their ideas into your business?

12. If you do not engage with stakeholders what is the reason? What obstacles do you face?

13. Besides engagement what does your company do to make sure research and innovation is done responsibly?

14. In which areas of your business do you foresee societal or ethical risks arising? Do you do anything to overcome these? Who evaluates this?

15. Can you describe how you evaluate what future impacts your innovation decisions might have beyond your firm?

16. How do you anticipate your innovation strategy will develop in the future? What obstacles do you foresee?

Our study's interpretivist approach is informed by previous research (Holstein \& Gubrium, 1995) and perceives an interview as a socially constructed event in which participants "articulate on-going interpretive structures" (p. 16). Accordingly, the interviewer acted as an expert facilitator who gave space to respondents to talk about their views through open-ended, topic-based questions (Silverman, 2006). This allowed the respondents to talk about topics that might even contradict each other (e.g. expressing business incentives beyond profit maximisation while at the same time lamenting a lack of resources and the need to balance responsibility with business survival). Such an approach allowed the interviewees to identify with multiple narrative positions (Arsel \& Thompson, 2011), and the researcher to explore how the thematically significant narrative constructions link with each other, and how they emerge. This enabled the formulation of a narrative pluralism, with respondents producing various accounts of their perception of what it means to innovate responsibly. As stated earlier, all the participants in this research were either owner/managers or co-founders with a vested interest in how the business is perceived. Therefore, it is possible that the interviews are subject to social desirability bias (Fisher, 1993).

Transcripts were systematically studied through an iterative process of coding and analysis. The first reading of the transcripts was quick and 


\section{Cristina Covello and Konstantinos Iatridis}

codes were generated indiscriminately. At one point during the initial coding stage this research had 51 codes that pointed to possible themes for further exploration. As research progressed, some codes were renamed or combined with other codes that revealed the same sentiment. After an initial coding, the process became more focused. Here, the researcher looked for data that fit with established codes while remaining open to new codes. Codes that ceased to accumulate data were set aside but not deleted. Deleting the codes would have prohibited their future use. Coding is not a linear process and a further reading of the transcripts may have prompted a new idea, strengthening the deleted code. The process of coding remained interactive and iterative until all the interviews had been coded. Once all the interviews had been coded they were reread. A final edit of the codes revealed the following three emergent themes: (1) unfamiliarity with the RI concept; (2) the challenge of stakeholder inclusion; and (3) beyond profit maximisation, personal incentives and visions of change.

The next section of this chapter is organised around these themes, which are described together with illustrative quotes from the interviewees that encapsulate their meaning. These themes capture the challenges and drivers that foodpreneurial SMEs may encounter when trying to use the RI framework.

\subsection{Findings}

\subsubsection{Unfamiliarity with the RI concept}

None of the participants had heard of the terms responsible innovation or Responsible Research and Innovation before the interview. This is not surprising as the concept is relatively new and there has been low diffusion of the concept at an SME level. Most participants defined the term by accounting for the words separately and then combining them to complete a conceptual definition. For example:

I haven't heard of responsible innovation before but I can imagine what it means as a set of words. Responsible: to consider ethics, morals and social impact. Innovation: the development of new products and services. So I guess responsible innovation would be the development of ethical products and services.

(Participant 9)

Another example illustrates this approach but also reveals a struggle to define the term:

Responsible innovation - I'm not sure what it means but I guess it would be the two words together. Hmmm - I'm having trouble articulating this. I think sometimes businesses are too focused on profits and 
they put ethics to one side. But actually if they were to focus on the ethics the rest would take care of itself.

(Participant 13)

Difficulty articulating the term was not uncommon. Most participants needed time to pause and think about their answers. This led to a distinction between those who defined RI in terms of desired outcomes. For example:

I think innovation is inherently good. All innovation has its benefits. In other words there is no bad innovation. I guess when you add the responsible part in you're talking about customer welfare and how innovation benefits society.

(Participant 16)

And those who included a process element as articulated here:

My understanding of responsible innovation is that it's about developing products and processes in a way that is ethically and environmentally sustainable.

(Participant 11)

Most participants understood that RI is about both processes and outcomes. They recognised RI as not only innovating for society but also how that innovation should be achieved. However, only one participant provided an indication as to what that process might look like.

I guess I see responsible innovation as building in the responsible element right at the beginning of the innovation process. So it's an added thing to consider. So for instance when creating a new product you would work from the ground up by making sure the ingredients are coming from an ethical source, that the processes to make it are energy efficient, that we use the least amount of packaging as possible. It's about compromise too and doing the best with the resources available.

(Participant 3)

One interviewee had done background research on RI prior to the interview and therefore his definition of the term was most closely related to definitions found in the literature.

I guess it's about creating a framework for decision-making that tries to encompass all the facets and impacts of innovation - other factors than financial. 
The distinguishing feature in his definition is the word "framework" which connotes a structured process for making ethical decisions. None of the interviewees mentioned stakeholders or stakeholder engagement in their definitions. As such, the interactive and mutually responsive aspect of RI was absent from the definitions provided.

\subsubsection{The challenge of stakeholder inclusion}

Deliberation with stakeholders on responsible decision-making proved inconsistent. There seemed to be tension between not having a complete understanding of who a stakeholder might be or how to engage with them, yet acknowledging stakeholder influence and the stakeholder as a source of innovation. Stakeholder engagement was generally informal and framed as networking rather than stakeholder engagement. For example:

We talk to the Greater London Authority and the Food Team to affect policy, we do a lot of networking and drinks... We do a lot of networking on urban ag [agriculture] and food tech.

(Participant 14)

I think doing talks and informal networking is the best way to engage with stakeholders.

(Participant 5)

Some participants related to stakeholder engagement in terms of building a community and fostering trust within that community.

We could definitely improve our engagement with stakeholders. We're in constant contact with the fishermen and with our members about the business and about how it all works and the logistics but we don't engage with them on social issues. Most of what we do is informal and anecdotal. But we have built up trust - not just with our members like I spoke about before but also with the fishermen... We've had to do some cultural navigating for sure - but mostly we've just taken our time to build up a certain level of trus.

(Participant 15)

Perhaps less explicit but still evident in dialogue surrounding stakeholder engagement was the idea of reciprocity.

We engage with the farmers. We have direct relationships with them and we get to learn about their issues and try and take those on board. So for example one of the guys we deal with in Ecuador has decided to take this project on with monkeys because there's an area that's being deforested that's both a monkey habitat and a cocoa growing area. He's 
married these issues and said if we can sell his cocoa then it's a double win. So we've said right - okay - and we've gone to Cocoa Runners who distribute chocolate from lots of different bean to bar chocolate makers to set up a promotion where they get a bunch of different makers on board to try making bars with these beans and see what everyone comes up with - sort of like a competition.

(Participant 8)

This story illustrates an innovative way to engage with stakeholders and suggests reciprocity between the company and the farmers that builds real partnership. These three attributes of stakeholder engagement in SMEs informality, trust and reciprocity - align with the idea of social capital as defined by Putnam (2001).

Russo and Perrini (2010) also believe that for SMEs stakeholder engagement is linked to the building of social capital and that social capital is a driver of sustainability from the SME perspective. These authors studied how social networks relate to corporate social responsibility (CSR) strategy and assert that SMEs form natural relationships with a range of stakeholders but that they do not exploit these relationships for competitive advantage. However, they argue that SMEs should use their social capital to enhance their CSR credentials through a more focused stakeholder approach (ibid.). Our findings corroborate those of Russo and Perrini (2010) as they suggest that corporate responsibility in SMEs is more closely related to social capital than to stakeholder salience theory (Mitchell et al., 1997).

Although all participants engaged with stakeholders from within their own firms and external stakeholders from the wider community, many participants had trouble identifying their stakeholders. In fact, some were not entirely sure what the term meant. One participant thought that stakeholder was synonymous with shareholder. He asked:

What do you mean by stakeholders? Do you mean my shareholders?

(Participant 13)

Another participant needed clarification:

Stakeholder - who do you define as stakeholders?

(Participant 9)

Still others did not classify their relationship building as stakeholder engagement.

I would totally be willing to engage with internal and external stakeholders on these [social] issues. I'll be honest with you that until now it hadn't occurred to me. 
This comment came despite the fact that upon further probing the participant revealed he indeed engaged on the social issues that affect his business.

We do speak about these [social] issues internally, in an informal way.

(Participant 1)

These examples point to a lack of familiarity with the stakeholder engagement concept. Importantly, this lack of knowledge does not create resistance to engagement. The theme of willingness was common amongst participants.

We're definitely willing to engage with internal and external stakeholders on these issues - even excited about it - but the question is when and how. I don't really know how I would go about engaging on these issues or what I would do with the information. I wouldn't know where to start in terms of knowing what to say or how best to approach these topics.

(Participant 3)

However, equally common were obstacles to engaging, like time constraints and the priority for solving more urgent business issues.

There's no time to engage! We have an informal advisory board but the focus is on not losing money - not ethical issues.

(Participant 2)

Yet, the participants also understood the business benefits for engaging on social issues.

Time is what holds us back from engaging more... But we realise the better we are at communicating with stakeholders the more the business will progress so we really need to do it.

(Participant 12)

Over half the interviewees acknowledged the influence of stakeholders on their businesses.

I think our partnership approach is also unique. We see everyone from our brewers to packagers to our accountants and lawyers as partners in the business which means we're all working toward a common goal.

(Participant 9)

Our values centre around creating long-term relationships with farmers. Actually we focus on lasting relationships with all our partners whether farmers, packaging producers, employees or even other associations like our involvement with the Vegan Association. 
Some participants also expressed how stakeholders have a direct impact on their innovations.

I think we'll continue to innovate by listening to the growers as a primary way of learning about the issues that we want to tackle. Of course new product development for us has to be kind of market driven so we need to be thinking about what people want to buy - and of course that's a benefit for the growers as well because if we can sell more chocolate we can buy more beans from them.

(Participant 8)

When we went to New York we met the guys from the New York City Parks department on their green roof. They gave us the crown jewels for learning how to set up a roof garden and now that we've paid our respects they're happy to collaborate with us. Any question I have on green roofs, bees and solar panels I now have a resource I can call on and that's tremendously valuable.

(Participant 19)

These examples show how the foodpreneurial SMEs use stakeholder engagement as a resource for researching and implementing new ideas despite the lack of a formal engagement strategy.

\subsubsection{Beyond profit maximisation, personal incentives and visions of change}

In the type of SMEs studied here, business drivers centre on the personal values of the owner/manager. Visions of creating change and the owner/ manager as change maker were evident, as were business incentives beyond profit maximisation. Spence and Rutherfoord's (2001) work helps to put these findings into perspective. They claim that SME entrepreneurs' business orientations can be described as profit maximisation priority, subsistence priority, enlightened self-interest priority or social priority. Briefly, profit maximisation refers to a drive for money, subsistence priority is based on long-term survival, enlightened self-interest refers to being active on social issues but in the knowledge that this could positively affect profit and social priority means that social values are embedded in business life and take priority over profit maximisation (ibid.). None of the participants in this research could be described by Spence and Rutherfoord's profit maximisation frame. Some participants fit their enlightened self-interest frame. However, most of the entrepreneurs can be described by the social priority frame, which embeds social issues into business life. For example:

[Our product] contains no sugar or sweeteners, nothing artificial. We see this as an alternative [in the market]. We think too many people are consuming sugar without thinking about it - or even knowing about 
it. Our vision is to help improve the health of the country, increase health and happiness and decrease obesity by providing an alternative to sugary drinks.

(Participant 5)

We started the business to pursue our interest in beekeeping but we quickly realised there was an appetite for sustainable local food production in cities. So that's really the core of our business - to produce a local food source sustainably and make people aware of it and continue to promote it - that is finding the best ways to produce local food in an urban environment.

(Participant 12)

That does not mean that the owner/managers discounted profit altogether, it is just that profit was not their top priority. This is evidenced here:

I'm not sure about an ethical dilemma. I mean we're not about profit at the expense of the environment or sustainability but we're not a social enterprise either.

(Participant 4)

When asked outright about their incentives for running their businesses responsibly the majority of subjects claimed personal moral conduct. This finding corroborates Jenkins' (2006) work that showed moral judgements outweighed business benefits as incentives for implementing CSR. Responses were generally quick and animated. For example:

What's my incentive? Well - being able to look in the mirror!

(Participant 14)

I think the real incentive for running our business this way comes down to treating people how you would want to be treated. I could act like a cunt and I would probably make more money - but I don't want to act like a cunt!

(Participant 10)

Our incentive for running our business in a responsible way is our moral compass.

(Participant 5)

These statements lead to another significant finding. None of the SMEs, not even the social enterprises, had a formal set of values or code of conduct yet half of the participants expressed values-driven decision-making. That means decision-making is ultimately made at the discretion of the owner/ manager and inevitably according to his or her personal ethics. 
Right now we don't evaluate the future impacts of our work. We don't exactly know - it's impossible to predict where we're going but if our culture and ethics are intact then we know we'll head in the right direction and we'll make the right decision based on our values.

(Participant 2)

But, we've got a good reputation so far and we operate fairly. We hope if we live by the spirit of our values we can beat other companies at their own game!

(Participant 9)

The incentive for running the business this way is simply because I couldn't imagine doing it any other way. Between my upbringing, my education, my respect for the planet - this is just how I want to do business.

(Participant 15)

Our findings suggest that foodpreneurial SMEs are driven by factors other than pecuniary reward, which creates a welcome platform for RI. However, it is possible that the personal incentives that drive decision-making could hinder RI processes if the results of the research process and stakeholder engagement conflict with the personal values and desires of the company's owner/manager.

\subsection{Discussion}

The extant literature on RI in industry has a tendency to concentrate on larger firms, relatively ignoring the SME context. Yet, SMEs form a significant part of the European and global economy, with the majority of firms falling into this category. Consequently, by analysing what these SMEs intuit about RI, the characteristics of their stakeholder engagement, their business motivation and their proclivity to innovate responsibly, this chapter enhances knowledge of how RI can be undertaken by this type of firm.

Our study corroborates previous findings (Chatfield et al., 2017) on RI awareness by demonstrating that, while many aspects of RI might be addressed by SMEs, the term itself is not well known. Thus, there might be cases where the subjects embrace RI principles without knowing it. This matters because, without using RI deliberately it will be coincidence if their innovation fulfils the needs of society. This is demonstrated in how many of the interviewees were not sure how to define a stakeholder or express how they engaged with them, but when probed could tell stories of how stakeholder influences have affected their business. Opposite to classic notions of stakeholder engagement that use a language of stakeholder salience based on legitimacy, power and urgency to prioritise stakeholder claims against the firm (Mitchell et al., 1997), our respondents told stories of building 


\section{Cristina Covello and Konstantinos Iatridis}

community, trust and reciprocity, which exemplify social capital. Perhaps these differences are the result of the foodpreneurial SMEs' stakeholder engagement process, which is informal, comes naturally and is even unintentional at times. Taken further, some of the interviewees expressed how they work with stakeholders to develop innovations. Due to the nature and size of their businesses, these SMEs are not engaged in high-level scientific research of the sort that dominates the RI discourse. Of course most collaborate with customers as a form of market research, but this is not necessarily innovative as most companies undertake customer feedback exercises. Still, many of the participants described more than simple customer research meant to improve their firm's offering and included stories that illustrated how engaging in research improves the community in which they operate, demonstrating in this way a propensity for RI.

Perhaps theories of stakeholder identification and salience are not necessary for these SMEs on account of their ability to network naturally within the communities they operate. While time and money constraints might impede a formal stakeholder prioritisation process, the informal networks they build as a process of product and business development are more appropriate to their size and structure. According to Pellé and Reber, "innovators are often driven by competition and by first-mover advantages that call for secrecy" $(2013$, p. 39). Our SMEs did not seem to suffer from this kind of competitive drive. Most of the participants expressed openness to sharing ideas, suggesting they would view the stakeholder engagement aspect of the RI process as complementary to their business objectives, rather than contradictory. Examples like Participant 8's cooperation with Ecuadorian farmers links to Hockerts et al.'s (2008) assertion that stakeholders in the SME setting are seen more like partners in the business than outsiders that need to be managed. Additionally, the stakeholder salience concept may actually be at odds with RI in that some researchers believe the idea of prioritising stakeholder claims disregards stakeholders that have legitimate claims on the firm (Derry, 2012). Furthermore, these marginal stakeholders may provide opportunity for innovation more in line with the principles of RI.

However, just because stakeholder identification and salience as described by Mitchell et al. (1997) do not fit within the context of RI in SMEs, it does not mean that the owner/managers should not take an active approach to stakeholder engagement. They already express how influential stakeholders are to their business and how they work with them to innovate so it would make sense for them to capitalise on the investments they are making to maximise the benefits of engagement. Doing so would result in an enhanced reputation and increase in confidence and loyalty, not to mention a more stable workforce and more sustainable business over the long term (Russo \& Perrini, 2010). In fact, their preoccupation with the day-to-day running of the business is precisely the reason they should invest in strengthening their networks. In this way, they can compensate for their resource constraints by building ever-stronger networks. 
Most subjects pointed to resource constraints as obstacles to engagement but their willingness to engage, particularly on societal challenges, provides fertile soil for RI to take hold. Maybe the greater obstacle to effective stakeholder engagement is the owner/managers' lack of knowledge for how to implement the deliberative aspect of the RI process. The owner/managers are the driving forces behind SMEs so choosing with whom they engage and how they engage is done very much in an image of themselves. That means that, for these SMEs, with their informal engagement processes, stakeholder salience is closely linked to the values and motivations of the owner/manager.

Part of what makes the businesses in this study unique is their vision for affecting change and motivations beyond profit maximisation. They already conduct their businesses responsibly, albeit on their own terms. Nevertheless, it would be a shame for RI to discourage this kind of thinking just because it might not fit within the RI framework. Perhaps RI policy would be more effective in tackling the reflective part of the RI process amongst SME owner/ managers so that they become aware of how their decisions impact society from multiple perspectives, before they embark on a deliberative process that is perceived as harder and more resource-intense to implement.

Anticipating future impacts and reflecting on the underlying motivations driving research and innovation are important aspects of the RI process. Therefore, participants were asked about their motivations and incentives for running their businesses responsibly. The primary incentive the subjects revealed was the fulfilment of their own moral code. Decision-making and problem solving were based on the entrepreneurs' individual values and motivations, which indicates a high level of personal control over their organisations. This is further evidenced by the lack of formal values or codes of conduct made available to the public and open to scrutiny. Most of the owner/managers attributed this to their size. However, while personal values guided the business and could be changed on a whim due to their lack of formality, not one of the participants had what Spence and Rutherfoord (2001) would describe as a profit maximisation priority. Some fit the enlightened self-interest priority but the majority were oriented toward the social priority. Despite none of the subjects prioritising profit maximisation, only half could articulate what societal challenges affected their business or what challenges their business ideas could tackle. In other words, they work toward a personal goal that aligns with their own vision of what "grand challenges" are most important.

For RI to work, it needs to clearly target agreed desired outcomes through a research and innovation process that involves some inward reflection but also much outward deliberation and responsiveness to make sure outcomes meet the needs of society. Therefore, the extent to which responsible business practices are linked to personal values and motivations unearths a potential conflict with RI. It appears there is a gulf between the individualistic decision-making in these SMEs and the idea of meeting their responsibilities to all stakeholders that may make embedding the RI process difficult, even if the end result of their business practices is ultimately good for society. 


\subsection{Limitations and conclusion}

This research is not exempt from limitations, which point towards possible directions for future research. The sample size of this study is not sufficient for gaining in-depth insights. More studies, with access to bigger samples, would provide a broader account of foodpreneurial SMEs' views on RI. Although our findings corroborate those from other sectors, more evidence is needed to improve the robustness of our claims. Furthermore, our interviews involved one subject who provided a single perspective on the drivers and challenges food SMEs face. Future studies could draw on additional sources of information to discuss these drivers and challenges. Another limitation stems from the fact that at times interviewees might want to appear altruistic or benevolent. It's possible that some of the subjects overstated their responsibility. They may have been apt to do this because of the nature of the study and because they are owner/managers trying to leave a good impression of their firm in the public.

Apart from its limitations, learning more about the subjects' incentives, motivations, stakeholder engagement and perceptions of RI provided scope for generating ideas on how RI could be implemented in SMEs of this kind. Even just establishing a better sense of what drives SMEs provides an opportunity for steering their responsible business practices toward tangible RI outcomes. More specifically, appealing to the SMEs' tendency to envision their businesses as agents of change by helping them build RI into their entrepreneurial story could make RI appealing to owner/managers, thereby proliferating the concept. This research suggests that the foodpreneurial SMEs in London are attuned to responsible business and that their business models could accommodate the proliferation of RI. Therefore, studying RI in the SME context has the potential for impacting dissemination of the concept to a wider audience.

\section{References}

Arsel, Z. \& Thompson, C. J. (2011). Demythologizing Consumption Practices: How Consumers Protect Their Field-Dependent Identity Investments from Devaluing Marketplace Myths. Journal of Consumer Research, 37(5): 791-806.

Auer, A. \& Jarmai, K. (2018). Implementing Responsible Research and Innovation Practices in SMEs: Insights into Drivers and Barriers from the Austrian Medical Device Sector. Sustainability, 10(1): 17.

Bogdan, R. B. \& Biklin, S. K. (1998). Qualitative Research for Education: An Introduction to Theory and Methods (3rd ed.). Needham Heights, MA: Allyn and Bacon.

Chatfield, K., Iatridis, K., Stahl, B., \& Paspallis, N. (2017). Innovating Responsibly in ICT for Ageing: Drivers, Obstacles and Implementation. Sustainability, 9(6): 971.

Creswell, J. W. (2009). Research Design. Qualitative, Quantitative and Mixed Methods Approaches (3rd ed.). Thousand Oaks, CA: Sage. 
Derry, R. (2012). Reclaiming Marginalized Stakeholders. Journal of Business Ethics, 111(2): 253-264.

Dreyer, M., Chefneux, L., Goldberg, A., von Heimburg, J., Patrignani, N., Schofield, M., \& Shilling, C. (2017). Responsible Innovation: A Complementary View from Industry with Proposals for Bridging Different Perspectives. Sustainability, 9(10): 1719.

European Commission. Entrepreneurship and Small and Medium-sized Enterprises (SMEs). http://ec.europa.eu/growth/smes/ (accessed 9 July 2018).

Fisher, T. (1993). The View from the Top: Chief Executives' Perceptions of Total Quality Management. Australian Journal of Management, 18(2): 181-195.

Fontana, A. \& Frey, J. H. (2005). The Interview. From Neutral Stance to Political Involvement. In N. K. Denzin \& Y. S. Lincoln (Eds.), The Sage Handbook of Qualitative Research (3rd ed.): 695-727. Thousand Oaks, CA: Sage.

Garst, J., Blok, V., Jansen, L., \& Omta, O. (2017). Responsibility versus Profit: The Motives of Food Firms for Healthy Product Innovation. Sustainability, 9(12): 2286.

Genus, A. \& Stirling, A. (2018). Collingridge and the Dilemma of Control: Towards Responsible and Accountable Innovation. Research Policy, 47(1): 61-69.

Gibbert, M., Hoegl, M., \& Valikangas, L. (2007). In Praise of Resource Constraints. MIT Sloan Management Review, 48(3): 15-17.

Gurzawska, A., Mäkinen, M., \& Brey, P. (2017). Implementation of Responsible Research and Innovation (RRI) Practices in Industry: Providing the Right Incentives. Sustainability, 9(10): 1759.

Halme, M. \& Korpela, M. (2014). Responsible Innovation Toward Sustainable Development in Small and Medium-sized Enterprises: A Resource Perspective. Business Strategy and the Environment, 23(8): 547-566.

Healey, M. J. \& Rawlinson, M. B. (1994). Interviewing Techniques in Business and Management Research. In V. J. Wass \& P. E. Wells (Eds.), Principles and Practice in Business and Management Research: 123-146. Dartmouth: Aldershot.

Hemphill, T. A. (2016). Responsible Innovation in Industry: A Cautionary Note on Corporate Social Responsibility. Journal of Responsible Innovation, 3(1): 81-87.

Hockerts, K., Morsing, M., Eder-Hansen, J., Krull, P., Midttun, A., Halme, M., Sweet, S., Davidsson, P., Sigurjonsson, O., \& Nurmi, P. (2008). CSR-Driven Innovation: Towards the Social Purpose Business. Frederiksberg: Center for Corporate Social Responsibility, CBS.

Holstein, J. \& Gubrium, J. (1995). The Active Interview. Thousand Oaks, CA: Sage. Iatridis, K. \& Schroeder, D. (2016). Responsible Research and Innovation in Industry: The Case for Corporate Responsibility Tools. Cham, Switzerland: Springer.

Jenkins, H. (2006). Small Business Champions for Corporate Social Responsibility. Journal of Business Ethics, 67(3): 241-256.

Kowitt, B. (2018). Inside the trillion-dollar war on Big Food. http://fortune.com/ 2015/05/21/the-war-on-big-food/ (accessed 3 July 2018).

Lubberink, R., Blok, V., van Ophem, J., \& Omta, O. (2017). Lessons for Responsible Innovation in the Business Context: A Systematic Literature Review of Responsible, Social and Sustainable Innovation Practices. Sustainability, 9(5): 721.

Martinuzzi, A., Blok, V., Brem, A., Stahl, B., \& Schönherr, N. (2018). Responsible Research and Innovation in Industry - Challenges, Insights and Perspectives. Sustainability, 10(3): 702. 


\section{Cristina Covello and Konstantinos Iatridis}

Mitchell, R. K., Agle, B. R., \& Wood, D. J. (1997). Toward a Theory of Stakeholder Identification and Salience: Defining the Principle of Who and What Really Counts. Academy of Management. The Academy of Management Review, 22(4): 853-886.

Newsdesk (2018). Pip \& Nut secures over $£ 1$ million in investment to drive next phase of growth. www.fdin.org.uk/2018/05/pip-nut-secures-over-1-million-ininvestment-to-drive-next-phase-of-growth/ (accessed 30 March 2019).

Owen, R., Stilgoe, J., Macnaghten, P., Gorman, M., Fisher, E., \& Guston, D. (2013). A Framework for Responsible Innovation. In R. Owen, J. Bessant, \& M. Heintz (Eds.), Responsible Innovation: 27-50. London: John Wiley.

Pandza, K. \& Ellwood, P. (2013). Strategic and Ethical Foundations for Responsible Innovation. Research Policy, 42(5): 1112-1125.

Pavie, X., Scholten, V., \& Carthy, D. (2014). Responsible Innovation: From Concept to Practice. Singapore: World Scientific.

Pellé, S. \& Reber, B. (2013). Theoretical Landscape. Paris: Governance of Responsible Innovation (GREAT) Project.

Putnam, R. D. (2001). Bowling Alone: The Collapse and Revival of American Community. New York: Simon and Schuster.

Russo, A. \& Perrini, F. (2010). Investigating Stakeholder Theory and Social Capital: CSR in Large Firms and SMEs. Journal of Business Ethics, 91(2): 207-221.

Saunders, M., Lewis, P., \& Thornhill, A. (2012). Research Methods for Business Students (6th ed.). Essex: Pearson Education.

Seale, C. \& Silverman, D. (1997). Ensuring Rigour in Qualitative Research. European Journal of Public Health, 7(4): 379-384.

Silverman, D. (2006). Interpreting Qualitative Data: Methods for Analysing Talk, Text and Interaction. London: Sage.

Spence, L. J. \& Rutherfoord, R. (2001). Social Responsibility, Profit Maximisation and the Small Firm Owner-manager. Journal of Small Business and Enterprise Development, 8(2): 126-139.

Stahl, B., Obach, M., Yaghmaei, E., Ikonen, V., Chatfield, K., \& Brem, A. (2017). The Responsible Research and Innovation (RRI) Maturity Model: Linking Theory and Practice. Sustainability, 9(6): 1036.

Stilgoe, J., Owen, R., \& Macnaghten, P. (2013). Developing a Framework for Responsible Innovation. Research Policy, 42(9): 1568-1580.

van de Poel, I., Asveld, L., Flipse, S., Klaassen, P., Scholten, V., \& Yaghmaei, E. (2017). Company Strategies for Responsible Research and Innovation (RRI): A Conceptual Model. Sustainability, 9(11): 2045.

Voegtlin, C. \& Scherer, A. G. (2017). Responsible Innovation and the Innovation of Responsibility: Governing Sustainable Development in a Globalized World. Journal of Business Ethics, 143(2): 227-243.

von Schomberg, R. (2013). A Vision of Responsible Research and Innovation. In R. Owen, J. Bessant \& M. Heintz (Eds.), Responsible Innovation: 51-74. London: John Wiley. 